Artigos

Volume 10 - $2020 \mid$ n. 8

\title{
O Financiamento da Educação Básica em Portugal e
}

\section{Brasil}

\author{
Amilka Dayane Dias Melo Lima \\ Magna França \\ Universidade Federal do Rio Grande do Norte (UFRN), Natal/RN - Brasil
}

\section{Resumo}

O artigo objetiva analisar os modelos de financiamento da educação básica implementados no Brasil e em Portugal. Apresentam-se as diretrizes do financiamento nesses países, a aplicação dos recursos em percentagem do Produto Interno Bruto (PIB). Conclui-se que, no conjunto de semelhanças, há o fato de serem adeptos das políticas promovidas pelos organismos internacionais. Relativo às diferenças, os dois países assumem perspectivas de gestão e fonte de recursos distintos. Ao comparar a despesa per capita em educação, o quadro atual é de limitação do Brasil, ou seja, Portugal apresenta um investimento por aluno significativamente superior.

Palavras-chave: Financiamento da educação básica. Brasil. Portugal.

\section{Funding for Basic Education in Portugal and Brazil}

\section{Abstract}

The article aims to analyze the basic education financing models implemented in Brazil and Portugal. The financing guidelines in these countries and the application of resources as a percentage of the Gross Domestic Product (GDP) are presented. It is concluded that, in the set of similarities, there is the fact that they are adepts of the policies promoted by international organizations. Regarding the differences, the two countries assume different management perspectives and sources of resources. When comparing per capita spending on education, the current situation is limited by Brazil, that is, Portugal has a significantly higher investment per student.

Keywords: Basic Education Funding. Brazil. Portugal. 
O Financiamento da Educação Básica em Portugal e Brasil

\section{Introdução}

A partir das últimas décadas do século $X X$, em vários países vêm ocorrendo alterações significativas no papel do Estado, oriundas das consequências das reformas empreendidas nos processos de decisão política, da globalização e do neoliberalismo. Os apontamentos e discussões sobre os efeitos desses fenômenos, nos diversos campos da sociedade, têm sido recorrentes, evidenciando, quase sempre, as questões sobre medidas de descentralização administrativa, política econômica, política mundial, padrões de consumo e homogeneização cultural.

No contexto das políticas econômicas globais, existe o estabelecimento de uma agenda fixa e global para a educação. Essa política é configurada no âmbito da mundialização do capital, materializada em meio às ações governamentais e à reestruturação do próprio capital. A educação não é um elemento neutro, mas produto da ordem vigente, portanto, é natural que sofra influências dessa conjuntura.

Os reflexos dessa conjuntura nas políticas educacionais são perceptíveis em meio aos objetivos dos organismos internacionais, entre eles, a Organização das Nações Unidas (ONU), Unesco, Fundo Monetário Internacional (FMI) e Banco Mundial. Tais organismos influenciam as políticas públicas por meio de uma agenda globalmente estruturada sob a justificativa da modernização, melhoria da qualidade, eficiência, transparência, eficácia, flexibilidade e qualidade com repercussões nos campos da gestão e financiamento (DALE, 2004).

Essa realidade é observada em vários países, entre eles, Portugal e Brasil que, desde o final do século $X X$, vivenciam um período de intensa reforma no campo da administração pública do Estado, com reflexos diretos nas políticas educacionais, haja vista o processo de integração à lógica mercantil na organização da administração dos serviços públicos, possibilitando maiores níveis de competitividade no contexto mundial.

É inegável a herança cultural que o Brasil herda dos seus colonizadores, destacandose: a língua, a religião católica (maioria entre os brasileiros), o modelo de produção agrícola baseado no latifúndio e monocultura, entre outros. Todavia, no que se refere à organização política do Estado, esses dois países possuem estruturas distintas. O Brasil é um país federalista com dimensão continental, administrativamente dividido a partir de entes federados (União, estados e municípios) que possuem relativa autonomia. No caso de Portugal, o poder central relaciona-se, diretamente, com as autarquias e sedes regionais. Apesar dessas diferenças "a reforma do Estado conduziu para a minimização de políticas efetivas na área social, tanto no Brasil como em Portugal" (MOREIRA, 2015, p. 53). Por meio da análise das políticas educacionais, especialmente do financiamento da educação, é possível compreender como se processa a ação do Estado, em face do contexto de reestruturação produtiva do capital.

Neste artigo objetiva-se analisar as semelhanças e diferenças existentes entre os modelos de financiamento da educação básica implementados no Brasil e em Portugal, considerando o contexto das reformas ocorridas a partir da década de 1990, motivadas pela agenda globalmente estruturada para a educação, em face da conjuntura internacional do avanço da globalização e do neoliberalismo. 
O Financiamento da Educação Básica em Portugal e Brasil

Apresentam-se as diretrizes do financiamento com base nas legislações regulamentadoras, o investimento aplicado em educação básica por cada um desses países em percentagem do Produto Interno Bruto (PIB), mediante consulta de indicadores disponibilizados nos portais eletrônicos da Organização para a Cooperação e Desenvolvimento Econômico (OCDE), denominado Education at a glance.

\section{Diretrizes do financiamento da educação básica em Portugal}

Conforme Silva et al. (2015), nas políticas educacionais do Estado português, é possível observar dois movimentos fundamentais: a adoção de novas formas de governação da educação e a crescente europeização das políticas educativas. Os autores ainda explicam que esses movimentos não são lineares e eles têm sido responsáveis por alterar as dinâmicas locais.

Nesse contexto, a Revolução dos Cravos ${ }^{1}$, que pôs fim ao regime do Estado Novo, dando início a um novo momento marcado pela a democracia, liberdade e igualdade, marca a evolução do Sistema Educativo português no século $X X$.

De acordo com Barroso (2003), no período da segunda república, iniciada com o fim do Estado Novo, destacam-se quatro ciclos que caracterizam a evolução da educação em Portugal. O primeiro é compreendido entre os anos de 1974 a 1976, denominado de Ciclo da Revolução, cujo objetivo principal era romper com todos os símbolos da ideologia salazarista em prol de uma sociedade democrática e socialista. Esse período é marcado pela instabilidade política que é traduzida pela drástica redução da capacidade de intervenção do Estado.

O segundo ciclo denomina-se de Ciclo de Normalização. Esse momento é marcado pela aprovação da nova Constituição da República (1976) até a promulgação da Lei de Bases do Sistema Educativo (LBSE) (1986). O citado autor destaca que esse período é marcado pelo retorno ao planeamento, à imposição do papel do Estado e ao fim das ideias revolucionárias mais instáveis do ciclo anterior.

O terceiro ciclo inicia-se no ano de 1986 e se desenvolve até o final do século XX. Esse período é caracterizado por uma fase de reforma, inicialmente, marcada pela necessidade de integrar Portugal no projeto da Comunidade Europeia, e, consequentemente, modernizar a educação. Posteriormente, ainda, nesse ciclo, tentou-se estabelecer um Pacto Educativo para o Futuro, mas não houve sucesso.

O quarto e último ciclo, com vigência no início do século $X X I$, marca uma fase de descontentamento, em que "a percepção de que a educação é um 'sector em crise, tem sido uma constante, antes e depois da instauração do regime democrático em 1974". Contudo, o que é significativo desse novo período é a passagem de um sentimento de uma "crise de problemas" para o de uma "crise de soluções" (BARROSO, 2003, p. 72).

Após quatro décadas de contínuas transformações ocorridas em cada um desses ciclos, a educação portuguesa vivenciou um crescimento significativo em sua oferta e qualidade, assim como aponta França, Cabrito e Pinhal (2014, p. 185). Para esses autores,

1 A Revolução dos Cravos ou Revolução 25 de Abril trata-se de um movimento político e social, ocorrido em 25 de abril de 1974 em Portugal, no qual depôs-se o regime ditatorial do Estado Novo, iniciando um processo de implementação do regime democrático, culminando em uma nova Constituição, de 25 de abril de 1976. 
O Financiamento da Educação Básica em Portugal e Brasil

Se há algo de que Portugal se pode orgulhar relativamente às últimas décadas é, definitivamente, o progresso que alcançou em termos educativos. Do início da década de 1970 aos nossos dias, a educação foi um dos vectores a que os portugueses mais atenção deram, sentindo que ela está por detrás de todo o processo de ascensão social e de desenvolvimento pessoal.

Nesse cenário pós-revolução, é a Constituição da República Portuguesa, promulgada em 1976, que mantém a matriz democrática, atribuindo ao Estado a responsabilidade de criar uma rede de estabelecimentos públicos de ensino que atenda às necessidades de toda a população (NOGUEIRA, 2014). De acordo com essa legislação, "todos têm direito ao ensino com garantia do direito à igualdade de oportunidades de acesso e êxito escolar" (Art. 74ª).

O artigo $74^{a}$ da Constituição Portuguesa (1976) dispõe que o Estado deve ser responsável por assegurar o ensino básico e universal, obrigatório e gratuito. Tal responsabilidade se traduz em um conjunto de tarefas, definidas no inciso II do mesmo artigo.

Essas responsabilidades não serão contempladas se o Estado não designar um financiamento próprio para tal. O financiamento público da educação portuguesa ocorre mediante transferências entre os vários níveis da administração central e local, de modo que seja possível dar suporte à oferta da educação.

Segundo Barroso (2003), o financiamento da educação é um fator elementar no controle da administração central em função do sistema educacional. O autor acrescenta que, majoritariamente, o financiamento público da educação básica em Portugal é realizado pelo governo central, pelo Ministério da Educação, e apenas uma pequena parte é constituída pelo poder local. Desse modo, esse Ministério "[...] é assim, o principal responsável pelo financiamento público da educação, sendo o financiamento das autarquias muito limitado, ou seja, inferior a 3\% em 1992" (BARROSO, 2003, p. 80).

Em Portugal, nos anos 1970, a Constituição foi o marco normativo que representou o desenvolvimento e a democratização. Apesar desse avanço, o contexto educacional, ainda nos anos 1980,

[...] mantinha-se, pois, altamente centralizado e muito confuso, sendo consensual a urgência de se aprovar uma Lei de Bases que viesse a dar coerência e orientar o sistema, em termos compatíveis com a Nova Constituição e com ideário democrático da Segunda República (PINHAL, 2012, p. 228).

$\mathrm{Na}$ década de 1980, o paradigma dominante era a descentralização e a desconcentração e, em 1986, a Lei de Bases do Sistema Educativo passa a ser o instrumento que materializava a reforma do papel do Estado com base nesses padrões. Essa Lei $n^{\circ} 46$ de 1986 determina que o Sistema Educativo deve se organizar de forma a "descentralizar, desconcentrar e diversificar as estruturas e acções educativas" (Art. $3^{\circ}$, alínea "g"). Para tal, - Estado, mediante o Ministério da Educação, será o responsável pela coordenação da política educativa, garantindo a necessária eficácia (art. 43).

Conforme Pinhal (2012), a partir da citada Lei foi introduzido, no sistema educativo português, um conjunto relevante de alterações, orientações, visando à descentralização, à desconcentração e à diversificação das estruturas e das ações educativas. No entanto, o autor considera que a Lei "[...] não concretizou as medidas necessárias ao desenvolvimento de seus princípios, tendo deixado muito (talvez demais) por conta dos sucessivos governos que viriam a aplicá-la" (PINHAL, 2012, p. 231). 
O Financiamento da Educação Básica em Portugal e Brasil

Essa mesma Lei reforça o modelo de gestão do financiamento público centralizado no Ministério da Educação, que, por sua vez, por meio do orçamento do Estado, provê os seus serviços centrais e regionais aos estabelecimentos de ensino público, bem como dispõem de subsídios ao ensino particular e cooperativo e às escolas profissionais.

Aos municípios, cabe a responsabilidade no financiamento do sistema educativo referente à construção, à manutenção e à complementação de algumas despesas de funcionamento dos estabelecimentos de ensino (pré-escolar e do $1^{\circ}$ ciclo do ensino básico), além de assegurar o transporte escolar.

A estrutura do financiamento da educação pública portuguesa ocorre pela desconcentração administrativa e territorial, sendo materializada da seguinte forma:

A administração e gestão da educação básica foi delegada para o órgão de Poder Local, assiste-se uma transferência de verbas do Orçamento do Estado (cerca de $90 \%$ corresponde, grosso modo, ao pagamento dos salários) e apenas uma pequena parte (cerca de 10\%) é de responsabilidade direta das autarquias e geridas pelas escolas (FRANÇA; CABRITO; PINHAL, 2014, p. 189).

A educação como um dos direitos dos cidadãos, consagrado na Constituição da República Portuguesa, é uma das prioridades do Orçamento do Estado. A distribuição das verbas pelas diferentes instituições educativas ocorre em função do número de alunos matriculados nas unidades escolares. Nessa dinâmica, observa-se que entre o Estado e o Poder Local existe uma relação indissociável, entre o financiamento e a gestão. Ao Poder Local e as suas instâncias, é atribuída a responsabilidade da gestão do financiamento do ensino básico (MOREIRA, 2015).

No contexto do financiamento da educação básica em Portugal, importa destacar o fato de esse país integrar a União Europeia. Esse grupo caracteriza-se, basicamente, por ser um bloco econômico, político e social, constituído por 28 estados-membros independentes e situados, principalmente, na Europa. Assim sendo,

[...] ao comparar o caso português sob a percepção de questões globais e locais específicas desses países, afirmo que as políticas para o financiamento e gestão da educação centram-se prioritariamente na articulação para o cumprimento das metas estabelecidas pela União Europeia e são acompanhadas por orientações prescritas e recorrentes da OCDE (MOREIRA, 2015, p. 55).

As metas estabelecidas por esses organismos estão relacionadas ao ideário neoliberal e, no caso Português, são acentuadas pelo "Pacto de Estabilidade e Crescimento2". Nesse contexto, Graça (2009) compreende que são aplicadas regras de mercado ou de quasemercado aos domínios da vida social e a diminuição das despesas públicas. Naturalmente, o financiamento da educação é marcado por esse contexto de flexibilização, visto que, em nome da "eficácia" do sistema, é preciso fazer mais e melhor com menos verbas.

2 "O Pacto de Estabilidade e Crescimento (PEC) foi introduzido como parte da terceira fase da União Económica e Monetária (UEM). Foi concebido para garantir a manutenção da sanidade das finanças públicas por parte dos países da UE após a introdução da moeda única. Formalmente, o Pacto de Estabilidade e Crescimento era, originalmente, composto por uma Resolução do Conselho Europeu (adotada em 1997) e dois regulamentos do Conselho, de 7 de julho de 1997, que estabelecem as modalidades técnicas (controle das situações orçamentais e coordenação das políticas económicas e aplicação do procedimento relativo aos défices excessivos)" (EUR-LEX, 2018). 
O Financiamento da Educação Básica em Portugal e Brasil

Em face da necessidade de contemplar essas metas, após a promulgação da Lei de Bases do Sistema Educativo, Lei ${ }^{\circ}$ 46/1986, diversas legislações complementares surgiram com o objetivo de aperfeiçoar a descentralização do Sistema Educativo português. Essas legislações proporcionam maior intervenção dos agentes locais, mediante a descentralização de competências.

É importante salientar que o Sistema Educativo Português alcançou melhorias expressivas ao longo do século XX e início do século XXI. No entanto, houve, nos últimos anos, uma crescente desresponsabilização do Estado com o investimento em educação, sendo este deficitário em relação às necessidades do país (FRANÇA; CABRITO; PINHAL, 2014).

\section{Diretrizes do financiamento da educação básica no Brasil}

A estrutura do financiamento da educação brasileira está diretamente relacionada ao formato federalista de organização do Estado e aos dispositivos legais que configuram o contexto do planejamento, da política e da gestão da educação pública. Associa-se, também, aos interesses sociais, econômicos e políticos.

Conforme Pinto (2000), o histórico do financiamento da educação brasileira é dividido da seguinte forma:

a) de 1549 a 1759, período que os Jesuítas tiveram exclusividade na educação pública e assinalou-se um afastamento da Coroa em relação ao financiamento da educação; b) da expulsão dos Jesuítas até o fim da República Velha (1930) na qual ocorreu a busca de fontes autônomas para a educação e a educação esteve por conta das dotações orçamentárias dos governos dos Estados e das Câmaras Municipais; e, c) da Constituição Federal de 1934 até a atualidade, caracterizado pela vinculação de um percentual mínimo de recursos tributários para a educação (PINTO, 2000, p. 46).

A Constituição Federal de 1988 e a Lei de Diretrizes e Bases da Educação Nacional (LDB), Lei $n^{\circ}$ 9.394/96, determinam as principais atribuições na divisão de responsabilidade no contexto do financiamento e administração do sistema educacional brasileiro.

A Constituição de 1988 caracteriza-se pela descentralização financeira, atrelada ao acréscimo da participação dos estados e, principalmente, dos municípios na arrecadação tributária e na receita disponível. Na divisão de responsabilidade, o art. 211 define que os municípios possuem atuação prioritária no Ensino Fundamental e na Educação Infantil, enquanto os estados e o Distrito Federal, no Ensino Fundamental e Médio, definindo formas de colaboração entre si. A União possui a obrigação pela organização e financiamento do ensino federal, prestando assistência técnica e financeira aos estados, Distrito Federal e aos municípios visando ao desenvolvimento de seus sistemas de ensino e ao atendimento prioritário à escolaridade obrigatória (Art. 212).

$\mathrm{Na}$ Constituição Federal de 1988, ficou estabelecido que a União deve aplicar, na manutenção e desenvolvimento do ensino, o mínimo de $18 \%$; os estados, o DF e os municípios, $25 \%$ da receita líquida, resultante de impostos, incluindo a proveniente de transferências. Uma parte do que é arrecadado pela União (18\%) é transferido para os estados e municípios. Os estados transferem, também, uma parte de sua arrecadação para os municípios. 
O Financiamento da Educação Básica em Portugal e Brasil

No conjunto de impostos a serem arrecadados entre todos os entes federados, aquele vinculado em nível municipal, é o menor. Logo, os municípios, especialmente aqueles com pouca capacidade orçamentária, tornam-se dependentes das transferências estaduais e federais. Além dos impostos constitucionalmente vinculados (18\% União, 25\% estados e municípios), a educação brasileira ainda conta com outra fonte de recursos, a contribuição social denominada de Salário-educação. Essa contribuição social instituída no ano de 1964 é destinada ao financiamento de planos, programas, projetos para a educação básica pública.

O sistema de financiamento da educação básica no Brasil é apresentado por Emendas Constitucionais e leis que apontam para a reforma na gestão de forma descentralizada. A União e os governos subnacionais são responsáveis pela partilha das responsabilidades, a exemplo, da política de fundos contábeis: Fundo de Manutenção e Desenvolvimento do Ensino Fundamental e de Valorização do Magistério (Fundef) e o Fundo de Manutenção e Desenvolvimento da Educação Básica e de Valorização dos Profissionais da Educação (Fundeb).

O Fundef vigorou de 1998 a 2006 e foi substituído pelo Fundeb, em vigência de 2006 a 2020, ambos são fundos de âmbito estadual (um fundo por Estado e Distrito Federal, num total de vinte e sete fundos), formado, na quase totalidade, por recursos provenientes dos impostos e transferências dos estados, do Distrito Federal e dos municípios, vinculados à educação por força do disposto no art. 212 da Constituição Federal. Dos recursos subvinculados por esses Fundos, conforme determina a legislação, são destinados o mínimo de $60 \%$ à valorização do magistério e $40 \%$ à manutenção do ensino.

A educação brasileira, portanto, conta com fonte de recursos variados, proveniente, principalmente, da receita, resultante de impostos arrecadados pela União, estados, Distrito Federal e municípios, do Salário Educação e outros recursos adicionais. Cada fonte desses recursos possui destinações diferenciadas, que necessitam de fiscalização para que haja a garantia do cumprimento dos percentuais mínimos vinculados. A análise da estrutura desse financiamento deve considerar os diversos dispositivos legais, seu contexto de formulação e a implementação.

A configuração da política de financiamento da educação em nosso país é baseada nos princípios da reforma educacional a partir da segunda metade da década de 1990, quando o governo federal implementou mudanças substanciais, especialmente na área de gestão e nas competências das três esferas de governo. O financiamento da educação torna-se, pois, um dos principais objetivos das políticas educacionais, voltados para a melhoria da qualidade da educação.

\section{Portugal e Brasil: o que os dados de investimento em educação básica revelam?}

Na tabela 1, os dados referem-se ao período 1998 a 2014 e evidenciam a percentagem do Produto Interno Bruto (PIB), relativa às despesas públicas com instituições educacionais de educação básica em Portugal e no Brasil, revelando um retrato macro da evolução do investimento público em educação nesses países. 
O Financiamento da Educação Básica em Portugal e Brasil

TABELA 01: DESPESAS PÚBLICAS EM INSTITUIÇÕES EDUCACIONAIS EM PERCENTAGEM DO PIB, POR ANO E NIVEL DE EDUCAÇÃO (1998-2014)

\begin{tabular}{|c|c|c|c|c|c|c|c|c|c|c|c|c|c|c|c|c|c|}
\hline \multicolumn{18}{|c|}{ Portugal } \\
\hline & 1998 & 1999 & 2000 & 2001 & 2002 & 2003 & 2004 & 2005 & 2006 & 2007 & 2008 & 2009 & 2010 & 2011 & 2012 & 2013 & 2014 \\
\hline Educação pré-primária & - & - & - & - & - & - & - & - & - & - & 0,37 & 0,40 & 0,41 & 0,39 & - & - & - \\
\hline Ensino primário, secundário e pós-secundário não terciário & 4,22 & 4,2 & 4,1 & 4,2 & 4,2 & 4,2 & 3,8 & 3,8 & 3,6 & 3,5 & 3,4 & 4,0 & 3,9 & 3,7 & 3,9 & 4,2 & 4,0 \\
\hline TOTAL & 4,2 & 4,2 & 4,1 & 4,2 & 4,2 & 4,2 & 3,8 & 3,8 & 3,6 & 3,5 & 3,8 & 4,4 & 4,3 & 4,1 & 3,9 & 4,2 & 4,0 \\
\hline \multicolumn{18}{|c|}{ Brasil } \\
\hline Educação pré-primária & - & - & - & - & - & - & - & - & - & - & 0,41 & 0,40 & 0,44 & 0,52 & - & - & - \\
\hline Ensino primário, secundário e pós-secundário não terciário & 3,11 & 3,7 & 3,0 & 2,9 & 2,9 & 3,4 & 2,9 & 3,3 & 3,8 & 4,0 & 4,1 & 4,3 & 4,3 & 4,4 & 4,6 & 4,4 & 4,1 \\
\hline TOTAL & 3,1 & 3,7 & $\mathbf{3 , 0}$ & 2,9 & 2,9 & 3,4 & 2,9 & 3,3 & 3,8 & 4,0 & 4,5 & 4,7 & 4,8 & 5,0 & 4,6 & 4,4 & 4,1 \\
\hline
\end{tabular}

No Brasil, houve crescimento da despesa do PIB com instituições educacionais de educação básica, especialmente até o ano de 2011. Desde 2012, essa despesa tem apresentado queda, no entanto ainda permanece superior ao que era no início da série histórica. Em Portugal, o crescimento foi pouco expressivo, considerando que apenas os anos de 2009 e 2010 apresentaram valores maiores do que 1998. E em 2014, o valor chegou a ser $0,2 \%$ menor do que estava em 1998. Esse movimento tem relação com o desempenho da economia nacional, bem como da opção política de cada gestão governamental, ou seja, as prioridades da agenda pública de cada país.

De acordo com estudos de Pinto (2005) e Abrahão (2005), no Brasil, a aplicação de percentuais mínimos constitucionais em todos os níveis da educação (básica e superior) não ultrapassam o equivalente a $5 \%$ do PIB. Nas últimas décadas, o aumento do investimento público em educação é um desafio.

Na proposta da Lei $n^{\circ} 10.172$, de 9 de janeiro de 2001, encaminhada ao Congresso Nacional, que aprovou o Plano Nacional de Educação (PNE) para o decênio de 2001-2010, constava o valor de $10 \%$ do Produto Interno Bruto (PIB). Porém, o parlamento aprovou apenas $7 \%$, e o então presidente Fernando Henrique Cardoso vetou esse aumento, o que repercutiu em sérios problemas à viabilização da implementação do PNE de 2001 a 2010.

O atual PNE (2014-2024), sancionado pela Lei no 13.005, de 25 de junho de 2014, foi precedido por movimentos da sociedade civil organizada, destacando as conferências municipais estaduais e em âmbito nacional, deliberando que o Brasil deveria ampliar o investimento público em educação pública de forma a atingir, no mínimo, o patamar de $7 \%$ do PIB no 5 o ano de vigência dessa Lei e, no mínimo, o equivalente a $10 \%$ do PIB ao final do decênio.

O regime fiscal, implementado no Brasil pelo presidente Michel Temer, por meio da Emenda Constitucional $n^{\circ}$ 95/2016, institui teto para os gastos públicos federais nos próximos vinte anos, situando o Brasil num estado de exceção econômica e regressão nos investimentos sociais. A educação é uma das áreas mais afetadas com o novo regime fiscal, comprometendo, diretamente, o aumento do investimento público em educação em percentagem do PIB e, consequentemente, a implementação do PNE (2014-2024).

Em Portugal, o PIB tem crescido nas últimas décadas de forma muito lenta, apresentando decréscimo nos últimos anos do governo de centro-direita. Este, por sua vez, possui uma política baseada na diminuição de recursos com cortes orçamentários, em decorrência da crise financeira vivenciada pelo país. Essa política de austeridade em Portugal baseia-se na "[...] racionalização de recursos, contenção orçamental, redução de encargos, reforço no orçamento comunitário e aumento da participação de empresas no financiamento 
O Financiamento da Educação Básica em Portugal e Brasil

global” (MOREIRA, 2015, p.30). Tal política, consequentemente, repercute na restrição orçamentária para a educação e,

[...] de facto, os valores totais gastos pelo Estado em educação, bem como as despesas que ele realiza em educação per capta ou a percentagem dessas despesas no PIB Português, diminuíram significante desde 2010 sendo que os valores actuais se encontram ao nível do que se verificava no início do século (CABRITO, 2017, p. 180).

Em Portugal, após o dia 25 de abril e durante o período da II República, houve um aumento considerável da despesa pública com educação. De acordo com Graça (2009), registrou-se uma elevação quatro vezes maior na despesa com o Produto Interno Bruto (PIB). Porém, ao observar-se o investimento dos últimos 150 anos, constata-se que o índice é muito baixo. Em decorrência disso, Portugal precisa fazer um esforço significativo para superar esse atraso (MOREIRA, 2015).

Nota-se que os valores totais de despesa em educação do Estado Português decresceram na série histórica 1998-2014 e, no Brasil, ocorreu o movimento contrário. No entanto, quando se analisa a despesa pública anual com instituições de ensino por aluno em dólar, mediante as informações disponíveis no Panorama da Educação, publicado pela Organização para a Cooperação e Desenvolvimento Econômico (OCDE) no ano de 2016 e indicador "B3.3", percebe-se a limitação da despesa pública em educação do Brasil em comparação a Portugal.

De acordo com a publicação da OCDE (indicador B3, tabela B3.3), no ano de 2013, em dólares americanos, utilizando a conversão do PIB per capita, a despesa pública de Portugal por aluno no ensino primário correspondia a \$7.212, no ensino secundário \$ 9.758 e póssecundário não terciário o valor de $\$ 9.874$. No Brasil, esses valores correspondiam a $\$ 3.826$, \$3.802 e \$3.852, respectivamente, aos níveis mencionados (OECD, 2016).

No Brasil, apesar do aumento com a despesa em educação ter sido observado entre 1998-2014, esses valores ainda são insuficientes, havendo necessidade de melhores resultados na aprendizagem dos alunos e na superação da negligência sócio-histórica das políticas educacionais.

As políticas educacionais e seus resultados, no Brasil e em Portugal, devem ser compreendidos à luz dos contextos históricos, uma vez que esse contexto reflete na atual conjuntura. No Brasil, os primeiros ensaios de educação formal começaram com a chegada dos jesuítas em 1549. Nesse ano, Portugal já possuía um sistema educacional bastante avançado em relação ao Brasil. Além disso, o modelo escravista colonial impactou, impetuosamente, o processo educacional e escolar brasileiro, enquanto Portugal se favorecia, economicamente, dessa política. É fundamental considerar essa distância histórica na análise do desenvolvimento das políticas educacionais entre esses dois países.

\section{Considerações finais}

No conjunto de semelhanças entre esses países, destaca-se o fato de ambos serem afetados pelas políticas recomendadas pelos organismos internacionais e das relações de mercado. No que concerne às diferenças, observa-se que Brasil e Portugal assumem perspectivas distintas de gestão e fonte de recursos à educação básica. 
O Financiamento da Educação Básica em Portugal e Brasil

No Brasil, constitucionalmente existe uma definição mínima de recursos federais, estaduais e municipais a ser aplicada na educação, materializado em meio a um mecanismo de corresponsabilidades entre os entes federados. No Estado português, o financiamento da educação é baseado em um sistema de transferências para os diferentes níveis da administração, que, por sua vez, gozam de relativa autonomia para executar seus orçamentos de forma descentralizada.

Os resultados das políticas de financiamento em educação desses países, mediante análise da despesa pública com educação básica em percentagem do PIB, revelam que, apesar de o Estado brasileiro ter demonstrado esforço, aumentando essa despesa nos últimos anos e a sua legislação assegurar percentuais de recursos mínimos a serem aplicados, o quadro atual ainda é de limitação em comparação à despesa per capita de Portugal.

As especificidades de cada um desses países, inclusive as históricas, condicionam a implementação das políticas públicas de modo que cada Nação é afetada de forma diferente pelos princípios econômicos do mercado, pela dinâmica do capitalismo e pelas inter-relações entre Estado, política e sociedade. No Brasil, como em Portugal, torna-se premente uma reformulação nas políticas educacionais, cuja proposta educacional esteja além dos interesses do mercado, a fim de que a educação não seja exclusivamente fruto de uma política de austeridade, desregulamentação e privatização para favorecer, especialmente, a economia mundial.

\section{Referências}

ABRAHÃO, Jorge. Financiamento e gasto público da educação básica no Brasil e comparações com alguns países da OCDE e América Latina. Educação \& Sociedade, Campinas, v. 26, n. 92, p. 841-858, out. 2005. Disponível em: <http://www.scielo .br/pdf/es/v26n92/v26n92a07.pdf>. Acesso em: 1 set. 2018.

BARROSO, João. Organização e regulação dos ensinos básico e secundário, em Portugal: sentidos de uma evolução. Educação \& Sociedade, Campinas, v. 24, n. 82, p.63-92, abr. 2003. Disponível em: <http://www.scielo.br/pdf/es/v24n82/a04v24n82.pdf>. Acesso em: 1 set. 2018.

DALE, Roger. Globalização e educação: demonstrando a existência de uma. Educação \& Sociedade, Campinas, v. 25, n. 87, p. 423-460, ago. 2004. Disponível em: <http://www.scielo. br/pdf/es/v25n87/21464.pdf>. Acesso em: 1 set. 2018.

EUR-Lex. Pacto de Estabilidade e Crescimento. 2018. Disponível em: <https://eurlex.europa.eu/summary/glossary/stability_growth_pact.html?locale=pt>. Acesso em: 1 set. 2018.

FRANÇA, Magna; CABRITO, Belmiro; PINHAL, João. O financiamento da educação básica: o caso de Brasil e Portugal. In: CABRITO, Belmiro et al. (Org.). Os Desafios de Internacionalização da Educação em países de Língua Portuguesa: Financiamento e Internacionalização. Lisboa: Educa, 2014. p. 175-198.

GRAÇA, Vasco. Sobre o financiamento da Educação: condicionantes globais e realidades nacionais. Revista Lusófona de Educação, Lisboa, v. 13, n. 13, jul. 2009. Disponível em: <http://revistas.ulusofona.pt/index.php/rleducacao/article/view/548>. Acesso em: 1 set. 2018. 
O Financiamento da Educação Básica em Portugal e Brasil

MOREIRA, Jani Alves da Silva. Políticas de financiamento e gestão da educação básica (1990-2010): os casos Brasil e Portugal. Maringá: Eduem, 2015. 356 p.

NOGUEIRA, Mário Oliveira. Mário Oliveira Nogueira: Mário Oliveira Nogueira. Revista Retratos da Escola, Brasília, v. 8, n. 14, p. 27-37, jun. 2014. Disponível em: <http://retratosda escola.emnuvens.com.br/rde/article/view/372>. Acesso em: 1 set. 2018

OECD. Organisation for Economic Cooperation and Development. Education at a Glance 2016: OECD Indicators. Paris: OECD Publishing, 2016. Disponível em: <https://www.oecdilibrary.org/education/education-at-a-glance-2016_eag-2016-en>. Acesso em: 1 set. 2018.

PINHAL, João. Os municípios portugueses e a educação: treze anos de intervenções (1991-2003). Lisboa: Fundação Calouste Gulbenkian, 2012. 788 p.

PINTO, José Marcelino de Rezende. Os recursos para a educação no Brasil no contexto das finanças públicas. Brasília: Editora Plano, 2000. 181 p.

PINTO, José Marcelino de Rezende. Os números do financiamento da educação no Brasil. Pro-posições, Campinas, v. 16, n. 3, p. 75-86, set./dez. 2005. Disponível em: $<$ https://www.fe.unicamp.br/pf-fe/publicacao/2328/48_dossie_pintojmr.pdf>. Acesso em: 1 ago. 2018.

SILVA, Manuela et al. (Org.). Pensar a educação. Lisboa: Educa - Organizações, 2015. 134 p.

Amilka Dayane Dias Melo Lima é doutora e mestre em educação pelo Programa de PósGraduação em Educação da UFRN (PPGEd). Especialista em educação pelo o IFRN e graduada em Pedagogia pela UFRN. Atualmente é estatutária da rede pública estadual de ensino do RN e da rede pública municipal de ensino da Prefeitura de Parnamirim/ RN.

ORCID: http://orcid.org/0000-0003-3402-8768

E-mail: amilkadayane@hotmail.com

Magna França possui graduação em Pedagogia pela Universidade do Distrito Federal (1973), mestrado em Educação pela Universidade Federal do Rio Grande do Norte (1998) e doutorado em Educação pela Universidade Federal do Rio Grande do Norte (2001). É professora titular da Universidade Federal do Rio Grande do Norte.

ORCID: http://orcid.org/0000-0002-4756-0991

E-mail:magnaufrn@yahoo.com.br 


\section{Editores do volume 10}

Márcia Aparecida Jacomini - Universidade Federal de São Paulo, Brasil

José Marcelino de Rezende Pinto - Universidade de São Paulo, Brasil

\section{Comitê Editorial}

Nalú Farenzena - Universidade Federal do Rio Grande do Sul, Brasil

Juca Gil - Universidade Federal do Rio Grande do Sul, Brasil

Theresa Adrião - Universidade Estadual de Campinas, Brasil

Ângelo Ricardo de Souza - Universidade Federal do Paraná, Brasil

\section{Conselho Editorial}

\section{Alejandro Morduchowicz}

Universidad Pedagógica, Provincia de Buenos Aires, Argentina

Andréa Barbosa Gouveia

Universidade Federal do Paraná, Brasil

Fernanda Saforcada

Universidade de Buenos Aires, Argentina

Jacques Velloso

Universidade de Brasília, Brasil

João Monlevade

Senado Federal, Brasil

Jorge Abrahão de Castro

Instituto de Pesquisa Econômica Aplicada / IPEA, Brasil

Lisete Regina Gomes Arelaro

Universidade de São Paulo, Brasil

Luis Carlos Sales

Universidade Federal do Piauí, Brasil

Luiz de Sousa Junior

Universidade Federal da Paraíba, Brasil

Luiz Fernandes Dourado

Universidade Federal de Goiás, Brasil

Magna França

Universidade Federal do Rio Grande do Norte, Brasil

Marcos Edgar Bassi

Universidade Federal de Santa Catarina, Brasil

Maria Angélica Pedra Minhoto

Universidade Federal de São Paulo, Brasil

Maria Beatriz Luce

Universidade Federal do Rio Grande do Sul, Brasil

Maria Dilnéia Espíndola Fernandes

Universidade Federal de Mato Grosso do Sul, Brasil

Nelson Cardoso do Amaral

Universidade Federal de Goiás, Brasil

Nicholas Davies

Universidade Federal Fluminense, Brasil

Robert E. Verhine

Universidade Federal da Bahia, Brasil

Romualdo Portela de Oliveira

Universidade de São Paulo, Brasil

Rosana Gemaque Rolim

Universidade Federal do Pará, Brasil

Rubens Barbosa de Camargo

Universidade de São Paulo, Brasil

Theresa Adrião

Universidade Estadual de Campinas, Brasil

Tristan McCowan

University of London, Reino Unido

Vera Jacob

Universidade Federal do Pará, Brasil

Vera Peroni

Universidade Federal do Rio Grande do Sul, Brasil

Vitor Henrique Paro

Universidade de São Paulo, Brasil

\section{Equipe editorial}

Apoio ao Comitê Editorial: Caio Cabral da Silva

Diagramação, Revisão de português e normalização: Edson Leonel de Oliveira

Revisão de inglês: Sabrina Ferreira

Fineduca - Revista de Financiamento da Educação

Associação Nacional de Pesquisa em

Financiamento da Educação

e-mail: revista.fineduca@gmail.com | site: http://seer.ufrgs.br/fineduca 